\title{
What is the current evidence for cost of waiting on the outpatient list for management/treatment of orthopaedic/ musculoskeletal complaints? A systematic review
}

\author{
Twizeyemariya $\mathrm{A}^{1,2 *}$, Morris $\mathrm{JH}^{3,4}$ and Grimmer $\mathrm{K}^{5,6}$ \\ ${ }^{1}$ International Centre for Allied Health Evidence (iCAHE), University of South Australia. GPO Box 2471, Adelaide SA Australia \\ ${ }^{2}$ University of Canberra, Australia \\ ${ }^{3}$ International Centre for Allied Health Evidence (iCAHE), University of South Australia. GPO Box 2471, Adelaide SA Australia \\ ${ }^{4}$ The Canberra Hospital, ACT, 2605, Australia \\ ${ }^{5}$ Physiotherapy Department, Stellenbosch University, Faculty of Medical and Health Sciences, Cape Town, 7500, Australia \\ ${ }^{6}$ Clinical Teaching and Education Unit at VITA, Flinders University, Australia
}

\begin{abstract}
Little is known about costs of waiting for orthopaedic outpatient specialist consultations. A subset of papers on costs of waiting was identified from the body of literature identified in a systematic scoping review registered with Prospero (registration CRD42016047332), with the aim of exploring the impact of waiting for orthopaedic outpatient specialist consultations. Medline, Embase, Pubmed, and NHS Economic evaluation database (NHS-EED) were searched from inception until February 2018. The systematic scoping search yielded 139 articles, of which four reported specifically on costs (papers published 2002, 2005, 2009, 2012). All papers reported on hip and/or knee complaints. Cost data was extracted, described and standardised as Australian dollars (AUD\$). This review identified limited, non-current evidence on economic costs of waiting for outpatient orthopaedic surgical consultations. Whilst heterogeneous cost items, timing of collection, and dispersion measures constrained synthesis, it appears that direct and indirect costs of waiting may be significant to patients and health systems. Pharmaceuticals were the most common cost (from $\$ 263-\$ 1,912$ ). Future research into costs of waiting for orthopaedic conditions should report standardised cost measures, taken at standard time periods throughout the waiting period.
\end{abstract}

\section{Introduction}

Musculoskeletal disorders are the second highest contributor to years lived with disability (YLDs) worldwide, after mental and emotional disorders [1,2]. Musculoskeletal disorders contributed $21.3 \%$ to worldwide YLDs in 2010 [1] and osteoarthritis is predicted to be the leading cause of disability by 2020 [2]. While rarely fatal, musculoskeletal conditions pose economic and personal burdens on individuals and society e.g. healthcare costs, disruption to daily life and lost productivity [3-6].

Adding orthopaedic patients to outpatient waiting lists for specialist consultations has been a deliberate move over the last decade by policy makers in developed countries, to manage the mismatch between increasing prevalence of orthopaedic conditions requiring specialist consultations, and limited numbers of orthopaedic surgeons and rheumatologists [4,7]. Whilst waiting lists might be an effective health systems way of protecting the daily workload of consultants [3], it is reasonable to suspect that long waiting times for specialist consultations pose unmeasured economic burdens for patients, healthcare systems and society [8-10]. For instance, patients may have out-of-pocket expenses for formal or informal care required to manage their condition whilst they are waiting. There are potential societal losses of productivity because of absenteeism from work $[11,12]$, job loss [13] or presenteeism [14]. To our knowledge, there is no review to date that explores the costs of waiting for specialist consultation for orthopaedic conditions.
This paper reports on a subset of data from a larger systematic scoping review, which investigated the peer-reviewed literature on the impact of waiting for orthopaedic care [15]. This paper reports on available data on the costs of being placed on an outpatient waiting list for orthopaedic consultation to individuals, healthcare systems and society.

\section{Methods}

\section{The evidence base}

The review was registered with Prospero (registration CRD42016047332), and the complete search methods were reported previously [15]. Database were searched from inception until February 2018. This systematic review was conducted to answer the broad question of 'impact of waiting for orthopaedic specialist appointment'. The search approach is summarised in Appendix 1.

${ }^{\star}$ Correspondence to: Twizeyemariya A, University of Canberra, Bruce Campus, University Drive, ACT 2617, Australia, Tel: +61 401540814; E-mail: asterie. twizeyemariya@canberra.edu.au

Key words: cost, orthopaedic, musculoskeletal, management, treatment, waiting list Received: July 10, 2018; Accepted: July 18, 2018; Published: July 21, 2018 


\section{Critical appraisal}

The National Health and Medical Research Council hierarchy of evidence was used to rank study designs [16]. Included articles were critically appraised by two independent reviewers using the appropriate Critical Appraisal Skills Program (CASP) checklists $[17,18]$.

\section{Data extraction}

Data was extracted on author name and publication date, country, study design, population characteristics (including affected body part), reasons for waiting, waiting time, cost collection date, items, method, perspective, and currency. The cost variables were classified as healthcare costs (e.g. pharmaceutical costs), direct and indirect patient costs (e.g. out-of-pocket on medical and privately funded care), community costs (e.g. meals, community transportation), and productivity loss costs including costs associated with absenteeism, presenteeism or job loss.

\section{Cost standardisation}

To deal with potential heterogeneity in the cost data in terms of date of publication, and country, of research, costs were standardised as Australian dollars, using the average of each currency exchange rate in the year that the costs were reported. The converted costs were brought forward in time to the 2016 value, using the Australian consumer price index as a measure of inflationary considerations. To account for differences in time points when costs were collected, all costs were valued at the beginning of the year in which they are reported using the Pharmaceutical Benefits Advisory Committee (PBAC) recommended discount rate of 5\% [19] where necessary. When the year for the costs collection was not specified, the costs were valued at two years prior to the publication of the paper, as a normal delay from the collection of the data to the publication [13].

\section{Results}

\section{Body of evidence}

The systematic scoping search yielded 139 articles, of which four reported specifically on costs (Figure 1). These studies formed the dataset analysed for this paper. The studies comprised one RCT [20] (published 2009) and three prospective observational studies [10,21,22] (published 2005, 2002, 2012 respectively). All studies were of moderate methodological quality [15] (Table 1).

Table 2 reports the cost data and demonstrates its heterogeneity. Perspectives were unclear in two studies $[10,20]$, one used a societal perspective [22] and the remaining one took a patient perspective [21]. Cost collection methods were by questionnaire $[20,22]$ or cost diary $[10,21]$. All studies investigated patients with hip complaints waiting for joint replacements, and one also included knee complaints (also waiting for joint replacement) [21].

Average waiting periods reported on three studies ranged from 2.4 months to 6.4 month $[10,20,22]$, and waiting for consultation was 5.8 months [22].

Table 1. Aetiology hierarchy

\begin{tabular}{|c|c|c|c|}
\hline Papers & NHMRC & $\begin{array}{c}\text { Critical Appraisal } \\
\text { CASP economic tool }\end{array}$ & PeDro \\
\hline Tuominen, et al. $[20]$ & II & N/A & $8 / 11$ \\
\hline March, et al. $[21]$ & III-3 & $9 / 14$ & N/A \\
\hline Fielden, et al. $[10]$ & III-3 & $9 / 14$ & N/A \\
\hline Rolfson, et al. [22] & III & $9 / 14$ & N/A \\
\hline
\end{tabular}

The lack of standard data collection for costs precluded metaanalysis. After standardising costs, the average total costs incurred whilst waiting on an orthopaedic outpatient list varied between AUD\$ 621 and AUD\$ 15,980 per year. Pharmaceutical costs were the most commonly-reported, from AUD\$ 263 to AUD\$ 1,912 per year (Table 3). Two studies compared pharmaceutical costs for patients with short, and long, waiting periods, although there were definitional differences in the waiting periods $[10,20]$. Long waiting was defined as either longer than six months [10] or more than three months [20], which underpinned the differences in total medication costs during the waiting periods.

Personal costs included out-of-pocket expenses for the Medicare schedule-actual fee gap when patients attended community healthcare providers, over-the-counter medicines, travel costs and home help/ gardening that they could not do because of their orthopaedic condition. These were reported in three studies $[10,21,22]$ and ranged from AUD\$ 839 to AUD \$2,758 per year. Other costs which may have been subsidised by community providers included home modifications, special equipment, government-funded homecare, home delivered meals and community transportation. These were reported in two studies [21,22] as AUD\$ 947 and AUD\$ 3,177 on average per year.

Society costs included productivity loss, reduction in income and revenue tax loss for the government. These were reported in two studies (between AUD\$10,530 and AUD\$11,473 per year) [10,22].

Only one study considered the whole spectrum of costs (community, societal, patient and healthcare costs) [22].

\section{Discussion}

This review identified four non-current studies, which in itself highlights the need for more current research into an area of increasing interest to patients, society and health systems. Despite their age (the oldest being 16 years old and the most recent being six years old), these studies consistently provide evidence of significant personal healthcare system and societal costs, whilst patients with hip or knee complaints wait for specialist orthopaedic consultation. Patients may consequently incur significantly increased personal direct and indirect costs than they would with more timely treatment, and they may be unable to contribute as anticipated to society because of worsening symptoms. Moreover, the treatment patients require when they eventually reach the 'top of the waiting list' may be more complex and costly, than the care required if received earlier in the waiting period. The effectiveness of 'later' treatment may also be reduced, if compared to the effects of timely treatment [23].

It is arguable whether, and how, the economic costs associated with lengthy waiting for outpatient specialist consultations are considered in the current demand management approach. For instance, it may be beyond the remit of hospital management to consider the effects of waiting on patients, such as direct and indirect costs of medication and interim treatments, their lifestyle choices, their capacity to self-manage, as well as lost opportunities for family and societal participation, employability and contribution to society. Moreover, the downstream impact on the broader health system may be too distant to be of concern to current governments or hospital management. However, if the evidence from this small number of non-current studies is indicative of the impact that delay in orthopaedic consultation has, it flags the need for alternative, more cost-efficient strategies in the short and long term, to better manage outpatient orthopaedic waiting lists for the benefit of all. 
Twizeyemariya A (2018) What is the current evidence for cost of waiting on the outpatient list for management/treatment of orthopaedic/musculoskeletal complaints? A systematic review

Table 2. Current evidence for cost of waiting for management/treatment of orthopedic/musculoskeletal complaints: reported cost items

\begin{tabular}{|c|c|c|c|c|}
\hline & Rolfson et al. [22] & March et al. [21] & Fielden, et al. [10] & Tuominen, et al. [20] \\
\hline Cost perspective & Societal & Patient & Not stated & Not stated \\
\hline Costing year & October 2005-December 2006 & During 1994 and 1995 & April 1999 and March 2002 & August 2002 November 2003 \\
\hline Cost information & $\begin{array}{l}\text { Average per patient per year before } \\
\text { the surgery and confidence interval }\end{array}$ & $\begin{array}{l}\text { Average per patient on the } 3 \text { month } \\
\text { before the surgery }\end{array}$ & $\begin{array}{l}\text { Mean without standard deviation } \\
\text { and median values over the period } \\
\text { of waiting }\end{array}$ & $\begin{array}{l}\text { Average per week and standard } \\
\text { deviation/average total cost on } \\
\text { the waiting period and standard } \\
\text { deviation }\end{array}$ \\
\hline Collection methods & Survey using a questionnaire & Survey using a cost diary & Survey using a cost diary & Survey using a questionnaire \\
\hline \multicolumn{5}{|l|}{ COST ITEMS } \\
\hline \multicolumn{5}{|l|}{ Healthcare costs } \\
\hline Pharmaceutical & $\checkmark$ & $\checkmark$ & $\checkmark$ & $\checkmark$ \\
\hline $\begin{array}{l}\text { Other costs (healthcare professional } \\
\text { visits, tests) }\end{array}$ & NR & $\checkmark$ & NR & NR \\
\hline \multicolumn{5}{|l|}{ Personal costs } \\
\hline $\begin{array}{l}\text { Out-of-pocket (on medical or } \\
\text { privately funded care) }\end{array}$ & NR & $\checkmark$ & $\checkmark$ & NR \\
\hline $\begin{array}{l}\text { Private home help, gardener, private } \\
\text { taxi/ travel cost, transportation }\end{array}$ & NR & $\checkmark$ & $\checkmark$ & NR \\
\hline $\begin{array}{l}\text { Special equipment, Home } \\
\text { modifications }\end{array}$ & NR & & NR & NR \\
\hline \multicolumn{5}{|l|}{ Community resources costs } \\
\hline Meals, transport, home care & NR & & NR & NR \\
\hline Transportation & $\checkmark$ & NR & NR & NR \\
\hline Home modification & $\checkmark$ & NR & NR & NR \\
\hline \multicolumn{5}{|l|}{ Indirect costs } \\
\hline Method to estimate indirect costs & $\begin{array}{l}\text { Used the value-of-lost-leisure-time } \\
\text { principle or the replacement costing } \\
\text { method when employed }\end{array}$ & & $\begin{array}{l}\text { Lost wage identified in the diary } \\
\text { or average wages adjusted for } \\
\text { times when leisure or household } \\
\text { activities were affected, rather than } \\
\text { employment }\end{array}$ & \\
\hline $\begin{array}{l}\text { Productivity loss (time away from } \\
\text { work or usual activities) }\end{array}$ & $\checkmark$ & NR & $\checkmark$ & NR \\
\hline Informal care & $\checkmark$ & NR & NR & NR \\
\hline Disability pension & $\checkmark$ & NR & NR & NR \\
\hline
\end{tabular}

Table 3. Current evidence for cost of waiting for management/treatment of orthopedic/musculoskeletal complaints: reported costs (AUD

\begin{tabular}{|c|c|c|c|c|c|c|c|c|c|}
\hline & \multicolumn{2}{|c|}{ Rolfson, et al. [22] } & \multicolumn{2}{|c|}{ March, et al. [21] } & \multicolumn{3}{|l|}{ Fielden, et al. [10] } & \multicolumn{2}{|c|}{ Tuominen, et al. [20] } \\
\hline Country & \multicolumn{2}{|c|}{ Sweden } & \multicolumn{2}{|c|}{ Australia } & \multicolumn{3}{|l|}{ New Zealand } & \multicolumn{2}{|c|}{ Finland } \\
\hline Study design & \multicolumn{2}{|l|}{ prospective } & \multicolumn{2}{|l|}{ Prospective } & \multicolumn{3}{|l|}{ Prospective } & \multicolumn{2}{|c|}{ Randomised control trial (RCT) } \\
\hline Population: Age & \multicolumn{2}{|l|}{ 26-95 years } & $63.3(\mathrm{SD}=11.7)$ & $70.4(\mathrm{SD}=7)$ & \multicolumn{3}{|l|}{$35-85$ years } & $66(\mathrm{SD}=9.8)$ & $64(\mathrm{SD}=10.1)$ \\
\hline Population: Size & \multicolumn{2}{|l|}{2,635} & 76 & 98 & 86 & 36 & 122 & 92 & 170 \\
\hline Body part & \multicolumn{2}{|l|}{ Hip } & Hip & Knee & Hip & & & Hip & \\
\hline Waiting reason & Consultation & Surgery & Surgery & Surgery & Surgery & & & Surgery & Surgery \\
\hline $\begin{array}{l}\text { Mean of waiting } \\
\text { time (month*) }\end{array}$ & $\begin{array}{l}5.8 \text { [95\% CI 5.4- } \\
6.01]\end{array}$ & $\begin{array}{l}4.7 \text { [95\%CI: } \\
4.6-4.9]\end{array}$ & NR & NR & NR & NR & 5.1 & $\begin{array}{l}2.4[95 \% \mathrm{CI}: \\
1.3-3.6]\end{array}$ & $\begin{array}{l}6.4 \text { month } \\
{[95 \% \text { CI: } 5.5-7.2]}\end{array}$ \\
\hline Costs & \multicolumn{2}{|c|}{$\begin{array}{l}\text { Reported last } 12 \text { month before the } \\
\text { surgery }\end{array}$} & \multicolumn{2}{|c|}{$\begin{array}{l}\text { Reported last } 3 \text { month before the } \\
\text { surgery normalized on } 12 \text { month }\end{array}$} & Group $\leq 6$ month & Group $>6$ month & & $\begin{array}{l}\text { Short waiting } \\
\text { group }(\mathrm{SWT}) \leq 3 \\
\text { month }\end{array}$ & $\begin{array}{l}\text { No fixed waiting } \\
\text { group (NFWT): } \\
>3 \text { month }\end{array}$ \\
\hline Healthcare costs & \multicolumn{2}{|c|}{2647 [95\%CI: $2,188-3,107]$} & $\begin{array}{l}1928[95 \% \text { CI: } \\
1,151-2,706]\end{array}$ & $\begin{array}{l}1,133[95 \% \text { CI- } \\
522-1,743]\end{array}$ & 404 (Median) & 503 (Median) & $\begin{array}{l}1,912 \\
\text { (Mean on } 12 \\
\text { month) }\end{array}$ & & \\
\hline Pharmaceutical & \multicolumn{2}{|l|}{263} & $\begin{array}{l}1095 \text { [95\% CI: } \\
653-1,536]\end{array}$ & $\begin{array}{l}56695 \% \text { CI[261- } \\
872]\end{array}$ & 404 & 503 & 1,912 & $\begin{array}{l}621 \text { [95\% CI: } \\
524-736]\end{array}$ & $\begin{array}{l}670 \text { [95\% CI: } \\
509-882]\end{array}$ \\
\hline Other costs & \multicolumn{2}{|c|}{ 2,384 [95\% CI:1,925-2,844] } & $\begin{array}{l}833 \text { [95\% CI: } \\
498-1,170]\end{array}$ & $\begin{array}{l}567[95 \% \mathrm{CI}: \\
261-871]\end{array}$ & NR & NR & NR & NR & NR \\
\hline Personal costs & \multicolumn{2}{|c|}{$1,326[95 \%$ CI: $1,100-1,552]$} & $\begin{array}{l}1468 \text { [95\% CI: } \\
876-2,060]\end{array}$ & $\begin{array}{l}\text { 839 [95\% CI: } \\
387-1,292]\end{array}$ & 312 & 848 & 2,758 & NR & NR \\
\hline $\begin{array}{l}\text { Community } \\
\text { resources costs }\end{array}$ & \multicolumn{2}{|c|}{ 1,477 [95\% CI: $1,266-1,688]$} & $\begin{array}{l}947[95 \% \text { CI: } \\
565-1,329]\end{array}$ & $\begin{array}{l}3,177[95 \% \text { CI: } \\
1,464-4,890]\end{array}$ & NR & NR & NR & NR & NR \\
\hline Indirect costs & \multicolumn{2}{|c|}{ 10,530 [95\% CI: 9,813-11,187] } & NR & NR & 2,548 & 3,486 & 11,473 & NR & NR \\
\hline $\begin{array}{l}\text { Average total } \\
\text { costs }\end{array}$ & \multicolumn{2}{|c|}{$15,980$ [95\% CI: $14,427-17,533]$} & $\begin{array}{l}4,343[95 \% \\
\text { CI:2,592-6,095] }\end{array}$ & $\begin{array}{l}5,149[95 \% \text { CI: } \\
2,372-7,925]\end{array}$ & & & 16,144 & $\begin{array}{l}621 \text { [95\% CI: } \\
524-736]\end{array}$ & $\begin{array}{l}670 \text { [95\% CI: } \\
509-882]\end{array}$ \\
\hline
\end{tabular}




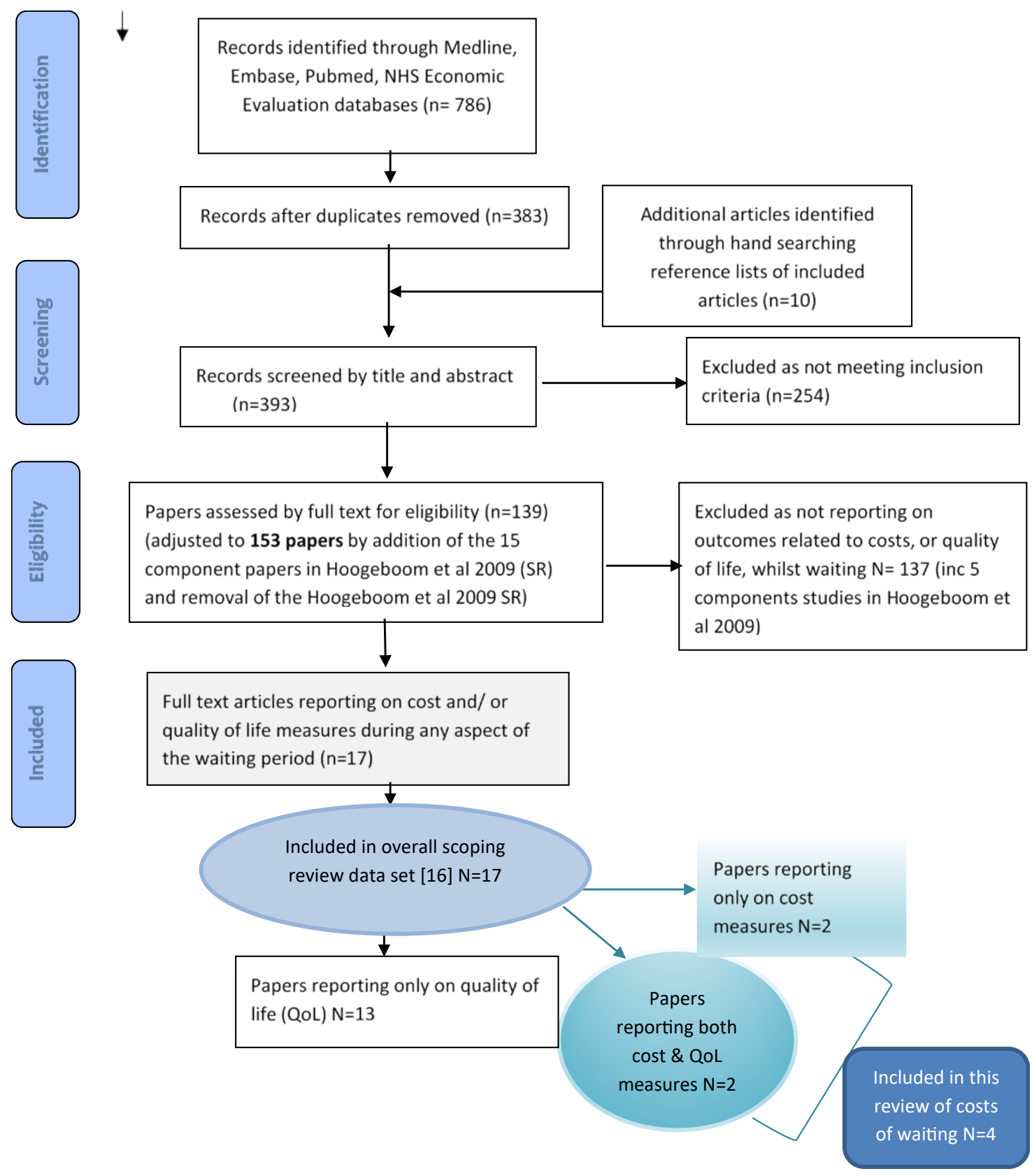

Figure 1. Consort diagram

This review found heterogeneity, inconsistency, missing information and lack of comparability in how costs of waiting were defined, measured and calculated. Consistent definitions of waiting are required (for instance 'short' or 'long' waiting), and future research should attempt to apply a standardized format of costs for economic analysis, to improve comparability and transferability of findings. Costs should also be routinely collected on productivity loss. Whilst absenteeism from work is well recognised and able to be recorded, there is also the potential for loss for productivity when people suffering orthopaedic conditions are present at work ('presenteeism'), but not able to perform to capacity due to pain and/or disability $[14,24]$.

This review identified papers reporting only on patients awaiting total hip or knee replacement. These findings are not generalisable to other musculoskeletal complaints (such as upper limb or spine) because of different pathologies and likely impact on daily activities. Moreover, it is anticipated that current costs would be higher than those reported in the non-current included literature because of inflation and increased unmet needs for patients with chronic conditions.

\section{Conclusion}

On this limited, non-current body of evidence, it appears that placing patients on an outpatient waiting list for a specialist consultation for an orthopaedic condition is not cost-neutral. Given the ageing population in Australia, and the increasing prevalence of musculoskeletal conditions requiring specialist consultation, it is essential that better ways of managing patients onto, and through, the outpatient waiting list be identified. Otherwise lists will continue to lengthen, more people will be impacted on by the need to wait for care, 
and costs of waiting will escalate. Better and more standard ways of collecting cost data will improve international understanding of which costs are incurred, at which point whilst waiting, and how much these are, whilst patients are on orthopaedic waiting lists. This knowledge will assist policy makers and health service planners to identify better ways of decreasing costs of waiting, and minimize the impact of waiting on individuals, health systems and society.

\section{Authorship and Author's contribution}

AT and JM for literature searching, critical appraisal; AT, JM, KG for debating and organizing the findings; drafting, reading subsequent drafts and editing the Manuscript.

\section{Acknowledgments}

Data management and formatting support from Ashley Fulton, Heath Pillen and Holly Bowen.

\section{Funding information}

No funding.

\section{Competing interest}

Authors declare no competing interests.

\section{References}

1. Vos T, Flaxman AD, Naghavi M, Lozano R, Michaud C, et al. (2012) Years lived with disability (YLDs) for 1160 sequelae of 289 diseases and injuries 19900-2010: a systematic analysis for the Global Burden of Disease Study 2010. Lancet 380: 2163 2196. [Crossref]

2. Woolf AD, Pfleger B (2003) Burden of major musculoskeletal conditions. Bull World Health Organ 81: 646-656. [Crossref]

3. Curtis AJ, Russell CO, Stoelwinder JU, McNeil JJ (2010) Waiting lists and elective surgery: ordering the queue. Med J Aust 192: 217-220. [Crossref]

4. Walters JL, Mackintosh S, Sheppard L (2012) The journey to total hip or knee replacement. Aust Health Rev 36: 130-135. [Crossref]

5. Australian Institute of Health and Welfare (AIHW) (2015) Arthritis, osteoporosis and other musculoskeletal conditions. Canberra: AIHW.

6. Australian Institute of Health and Welfare (AIHW) (2014) Arthritis and other musculoskeletal conditions across the life stages. In: Arthritis Series no.18. PHE 173, Canberra: AIHW.

7. Morris J, Grimmer-Somers K, Kumar S, Murphy K, Gilmore L, et al. (2011) Effectiveness of a physiotherapy-initiated telephone triage of orthopedic waitlist patients. Patient Relat Outcome Meas 2: 151-159. [Crossref]

8. Morris JH, James RE, Davey R, Waddington G (2015) What is orthopaedic triage? A systematic review. J Eval Clin Pract 21: 128-136. [Crossref]
9. Mandzuk L, McMillan D, Bohm E (2010) The Bone and Joint Decade in Canada A look back and a look forward. International Journal of Orthopaedic and Trauma Nursing 14: 12-17.

10. Fielden JM, Cumming JM, Horne JG, Devane PA, Slack A, et al. (2005) Waiting for hip arthroplasty: economic costs and health outcomes. J Arthroplasty 20: 990-997. [Crossref]

11. Johnson EC, Horwood J, Gooberman-Hill R, Bohm E, Dunbar MJ, (2014) Conceptualising time before surgery: The experience of patients waiting for hip replacement. Soc Sci Med 116: 126-133. [Crossref]

12. Conner-Spady BL, Marshall DA, Hawker GA, Bohm E, Dunbar MJ, et al (2014) You'll know when you're ready: a qualitative study exploring how patients decide when the time is right for joint replacement surgery. BMC Health Serv Res 14: 454. [Crossref]

13. Bohm ER (2009) Employment status and personal characteristics in patients awaiting hip-replacement surgery. Can J Surg 52: 142-146. [Crossref]

14. Jones C, Payne K, Gannon B, Verstappen S (2016) Economic Theory and SelfReported Measures of Presenteeism in Musculoskeletal Disease. Curr Rheumatol Rep 18: 53. [Crossref]

15. Morris J, Twizeyemariya A, Grimmer K (2017) The Cost of Waiting on an Orthopaedic Waiting List: a scoping review. Asia Pacific Journal of Health Management 12: 2

16. Merlin T, Weston A, Tooher R (2009) Extending an evidence hierarchy to include topics other than treatment: revising the Australian'levels of evidence'. BMC Med Res Methodol 9: 34. [Crossref]

17. Critical Appraisal Skills Programme (CASP) (2014) 12 questions to help you make sense of cohort study. Critical Appraisal Skills Programme (CASP). CASP Checklists.

18. Critical Appraisal Skills Programme (CASP) (2014) 11 questions to help you make sense of a trial. Critical Appraisal Skills Programme (CASP), CASP Checklists,

19. Pharmaceutical Benefits Advisory Committee (2016) Guidelines for preparing a submission to the Pharmaceutical Benefits Advisory Committee (Version 5.0) Canberra: Australian Government Department of Health and Ageing.

20. Tuominen U, Sintonen H, Hirvonen J, Seitsalo S, Paavolainen P, et al. (2009) The effect of waiting time on health and quality of life outcomes and costs of medication in hip replacement patients: a randomized clinical trial. Osteoarthritis and Cartilage 17: $1144-1150$.

21. March L, Cross M, Tribe K, Lapsley H, Courtenay B, et al. (2002) Cost of joint replacement surgery for osteoarthritis: the patients' perspective. J Rheumatol 29: 10061014. [Crossref]

22. Rolfson O, Ström O, Kärrholm J, Malchau H, Garellick G (2012) Costs related to hip disease in patients eligible for total hip arthroplasty. J Arthroplasty 27: 1261-1266. [Crossref]

23. Barua B, Esmail N, Jackson T (2014) The effect of wait times on mortality in Canada: Fraser Institute.

24. Brooks A, Hagen SE, Sathyanarayanan S, Schultz AB (2010) Edington DW Presenteeism: critical issues. Journal of Occupational and Environmental Medicine 52: 1055-1067.

Copyright: (C2018 Twizeyemariya A. This is an open-access article distributed under the terms of the Creative Commons Attribution License, which permits unrestricted use, distribution, and reproduction in any medium, provided the original author and source are credited. 